\title{
Os contos de fada e sua contextualização: \\ os clássicos e a indústria cultural
}

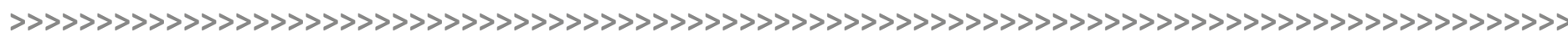

\author{
Maria Angélica Seabra Rodrigues Martins*
}

Gláucia Mariana Reis**

\begin{abstract}
Resumo:
Os contos de fada são utilizados, há muito tempo, como transmissores de valores morais referentes à época em que se situam, embora pouco se questione as influências que os contos sofreram e que também deixaram a partir do contexto em que se inserem. Neste artigo pretende-se - com o auxílio teórico-metodológico dos conceitos bakhtinianos de polifonia e dialogismo, além da intertextualidade proposta por Kristeva, na década de 1960, e dos elementos apresentados pela semiótica greimasiana - analisar como a influência de outras obras, do momento histórico-social, e da ideologia do próprio escritor constroem um discurso-texto, de acordo com os ditames da época em que os contos de fada foram produzidos, propiciando novos olhares, novas leituras sobre os clássicos, que, como obra, perduram há séculos.
\end{abstract}

\section{Palavras-chave:}

Contos de fada. Clássicos. Intertextualidade. Semiótica. Educação.

\section{Summary:}

Fairy tales have long been used as transmitters of morals and values related with the time they were composed, but little is questioned about the influences that the stories suffered by the context in which they operate. So reading this material, supported in the studies of intertextuality as a way to aid in education, which is often used by teachers and also something that can be analyzed by ordinary readers in the study of intertextuality, open doors for detailed analyzes of the influences that fairy tales have suffered. These influences can be whether by social, historical, religious, economic, and ideological contexts, but primarily by offering new perspectives and readings of the fairy tales.

\section{Keywords:}

Fairy tales. Classics. Intertextuality. Semiotics. Education.

\section{Introdução}

A partir do que é publicado hoje, são muitos os estudos a respeito das transformações que acontecem nos contos de fada, sejam eles por contextos socioculturais ou por adaptações motivadas pela indústria cultural que, na maioria das vezes, visa a um fim econômico, desvinculado do papel original de transmissor de valores dos contos de fada. Ao longo do tempo, as narrativas, devido a seu caráter oral, modificaram-se de acordo com as necessidades de cada época.

\footnotetext{
* > Doutora Docente de Língua Portuguesa dos cursos de Radialismo, Jornalismo e Relações Públicas da Faculdade de Arquitetura, Artes e Comunicação (FAAC) e da Faculdade de Ciências (FC) da UNESP - Bauru/SP. E-mail: masrm@uol.com.br

** > Pedagoga graduada pela Faculdade de Ciências da UNESP - Bauru/SP. E-mail glauciamarireis@hotmail.com
} 
Assim, nota-se que as adaptações são ocasionadas por intenções sociais, políticas, culturais, econômicas e morais, conduzindo por vezes à negação da realidade, desvinculadas dos modelos arquetípicos propostos pelos contos originais, possuindo outros valores que diferem dos modelos originais. Caso sejam comparadas às versões de Perrault e dos Irmãos Grimm para um mesmo conto, como A Gata Borralheira ou Cinderela, observam-se transformações de acordo com a época e, como se pode notar no caso dos textos relacionados e reescritos pelos Irmãos Grimm, por exemplo, a religião predomina sobre a imaginação e a criatividade Essa postura se explica, devido ao luteranismo presente nos reinos da hoje Alemanha, que exercia poder sobre as escolas e sobre os valores que seriam transmitidos às crianças. Como Lutero combateu sobremaneira todos os elementos pagãos da sociedade, como bruxas, magos, duendes, feiticeiros, naturalmente esses seres não aparecerão nas estórias dos Irmãos Grimm, a não ser na representação das personagens más.

$\mathrm{Na}$ atualidade, muitos desses contos de fada considerados clássicos estão sendo recriados pela indústria cultural, que reconstitui as estórias em filmes, livros, gibis, desenhos animados, desvinculados dos valores tradicionais e da figura do herói, cujo percurso de reveses e dificuldades é percorrido, apresentando a superação à medida que o protagonista aprende as lições necessárias a seu crescimento pessoal. Observa-se que há um movimento nas adaptações motivadas pelo cinema e pelos livreiros, de substituição de valores considerados "ultrapassados" para determinado público. Os contos de fada, nesse aspecto, transformaram-se em produto, cujo objetivo maior é a obtenção de lucro; ou seja, o modelo capitalista apropriou-se dessas narrações e as transformou em novos modelos desvinculados dos propósitos iniciais de transmissão de valores.

É pela importância que têm os contos de fada na vida das crianças que se busca a necessidade de compreensão das mudanças que neles ocorrem e a importância da retomada dos clássicos, em um trabalho de comparação entre as estórias, procurando conduzir a criança à compreensão das diferenças entre uma versão e outra. Para o professor, conhecer o processo de transformação, as variações e a utilização original dos contos, possibilitará uma escolha mais adequada das estórias e do processo a ser desenvolvido em suas narrativas, o que lhe permitirá um trabalho mais efetivo no tocante às inferências, por parte das crianças, auxiliando também no desenvolvimento de seu próprio raciocínio lógico.

Assim, este artigo propõe-se a discutir a questão dos aspectos histórico-sociais pelos quais os contos de fada podem ser influenciados, tendo como base estudos sobre o dialogismo, a polifonia, e a intertextualidade sob a ótica de Bakhtin e seus seguidores, e os elementos manipulatórios, temáticos e figurativos apresentados pela semiótica greimasiana. Também, é feita uma comparação literária entre os contos de fada originais e os veiculados pela empresa Disney.

\section{O texto e a intertextualidade}

Tânia Franco Carvalhal, em seu livro, A Literatura Comparada (1986), apresenta um método para o professor analisar livros que apresentam a mesma temática. No caso desta pesquisa, optou-se por privilegiar o estudo comparativo dos contos de fada sob uma perspectiva diacrônica, considerando que eles refletem as evoluções econômico-sociais no decorrer do tempo sob as influências dos mais variados contextos e da ideologia de quem os narrou. Portanto, é possível

dizer, então, que a literatura comparada compara não pelo procedimento em si, mas porque, como recurso analítico e interpretativo, a comparação possibilita a esse tipo de estudo literário uma exploração adequada de seus campos de trabalho e o 
alcance dos objetivos a que se propõe. Em síntese, a comparação, mesmo nos estudos comparados, é um meio, não um fim. (CARVALHAL, 1986, p. 7).

Dessa forma, observa-se que, por meio das transformações que se manifestam nos contos de fada, em cada época, quer sejam nos valores, na moral; ou, ainda, no retrato dos hábitos e costumes de uma sociedade, pode-se conhecer como viviam as pessoas e o que era valorizado por elas naquele momento histórico específico. A retomada de um texto por determinado escritor de época diferente, segundo Carvalhal (1986, p. 54), nunca é inocente, pois é repleta de certa intencionalidade que objetiva dar continuidade ao texto, transformá-lo, modificá-lo em relação ao texto antecessor, reinventando-o, renovando-o, atualizando-o.

A literatura comparada atua como um estudo de comparação entre literaturas de diferentes áreas linguísticas, levando em conta fatores culturais, econômicos, sociais, políticos, capazes de influenciar a literatura de uma determinada época. Ela "quebra" as fronteiras do tempo, dos gêneros, das línguas, de território, e busca um comparativismo também entre outras áreas do conhecimento, como a arte, o cinema, a música etc. A literatura comparada possui tendências interdisciplinares, pois estabelece relações com diversas manifestações artísticas e literárias; tendências interdiscursivas, pois relaciona diversas áreas de conhecimento; e também uma relação intersemiótica, tendo seu foco no quadro literário.

Fiorin (2006) ao analisar as teorias do formalista Bakhtin, afirma que a dialogia é um dos processos da literatura comparada, pois possibilita a observação das relações dialógicas de diversos textos de diferentes épocas ou mesmo simultâneos. Assim, a língua, sendo concreta e viva, tem a propriedade de ser dialógica, bem como todos os enunciados no processo de comunicação; ela é sempre firmada no discurso do outro e, inevitavelmente, também na palavra do outro. Para se construir um discurso, o discurso alheio é levado em consideração e este se torna parte do seu, tornando, assim, o enunciado, algo com relações de sentido, a partir de textos que dialogam entre si.

Marx (1992) também enfatizava a relação do contexto, das condições de vivência, como fatores que poderiam influenciar o discurso, tornando-se algo particular, muitas vezes imperceptível:

É em virtude do pensamento ser o pensamento de determinado indivíduo, que ele é e mantém o seu pensamento, determinado não só pela sua individualidade como também pelas condições em que vive; é, portanto, inútil que o indivíduo pensante se entregue aos meandros de uma longa reflexão sobre o pensamento em si, para poder declarar que o seu pensamento é verdadeiramente o seu próprio pensamento, a sua propriedade, pois o pensamento é, automaticamente, seu, o seu próprio, um pensamento determinado particularmente. (MARX, 1992, p. 29, grifo nosso).

Assim como o pensamento é particular, a construção do discurso de determinado indivíduo também o é e estará sempre impregnado de outras influências, de outros discursos e de outras ideologias; são vários os textos de uma cultura que se instalam em um único texto, definindo-o e modelando-o de acordo com o enunciador:

Em resumo, Bakhtin concebe o dialogismo como o princípio constitutivo da linguagem e a condição do sentido do discurso. [...] Em outros termos concebe-se o dialogismo como o espaço interacional entre o eu e o tu ou entre o eu e o outro, no texto. Explicamse as frequentes referências que faz Bakhtin ao papel do "outro" na constituição do sentido ou sua insistência em afirmar que nenhuma palavra é nossa, mas traz em si a perspectiva de outra voz. (BARROS; FIORIN, 1999, p. 2-3). 
Segundo Barros e Fiorin (1999, p. 5), as diversas vozes presentes em um texto são conhecidas como polifonia, ao contrário dos textos monofônicos em que o discurso alheio não é notado, pois se esconde através de uma única voz. Existem, portanto, textos polifônicos e monofônicos. Corrales em seu artigo A intertextualidade e suas origens esclarece que:

Para Bakhtin o sujeito perde seu papel principal no enunciado e é substituído por duas vozes sociais que fazem dele um sujeito histórico e ideológico; e considera esse dialogismo como princípio constitutivo da linguagem e a condição de sentido do discurso. $\mathrm{O}$ autor introduz o estatuto da palavra como uma unidade mínima da estrutura; para ele o texto deve ser situado na história e na sociedade. A palavra literária é então a intersecção das superfícies textuais. (CORRALES, 2010, p. 7).

Kristeva, sob influência dos estruturalistas e, principalmente, de Roland Barthes, na década de 1960, retoma essas questões propostas por Bakhtin, pois já mesclavam formalismo com estruturalismo, e "[...] deslocou a tônica da teoria literária para a produtividade do texto" (KRISTEVA, 1968). O termo intertextualidade foi criado por ela na Revista Tel Quel (1968), afirmando que: "Qualquer texto se constrói como um mosaico de citações e é absorção e transformação de outro texto” (KRISTEVA, 1968, p. 80-83). Dessa forma, o diálogo entre os variados discursos que se estabelecem em um texto e que o definem são diálogos que se completam, que respondem um ao outro, no processo da intertextualidade, possibilitando a derivação do texto, com as vozes internas do discurso reproduzindo esses diálogos.

Resumidamente, a intertextualidade é o modo de incorporar diversos textos em um único, transformando-o ou reproduzindo-o. Fiorin (2006) afirma que há três constituintes da intertextualidade: a citação, utilizada para afirmar ou completar o texto; a alusão, que serve para a reprodução de construções sintáticas; e a estilização, que reproduz os mesmos estilos de outrem. Esses três processos, marcados nos discursos, permitem a observação dos constituintes dos textos, as vozes e os discursos que lhe são alheios.

Como o texto dialoga com outros textos, sua essência é social; ele não é fechado, mas, sim, um local de trocas de enunciados que podem ser históricos e conflitantes, dando voz às várias classes sociais que o utilizam, de acordo com sua moral, suas ideologias, geralmente mascaradas no discurso; ou seja, na maior parte das vezes, a ideologia que o texto carrega, oriunda do ideal de uma classe, seja ela dominante ou dominada, e está oculta, tornando o enunciado de característica monofônica.

\section{Os contos de fada e sua formação discursiva}

Para compreender o processo de produção de um texto, buscam-se explicações, além das questões tratadas nos estudos bakhtinianos, também na semiótica greimasiana, enquanto estudo dos sentidos do discurso, observando-se a composição de seu quadro significativo. Martins (2009, p. 23) esclarece que a semiótica greimasiana aborda a verdade do texto que envolve enunciador e enunciatário, e objetiva sua "[...] ênfase nos estudos das relações intersubjetivas que tratam da manipulação do destinatário pelo destinador." Assim, nessa relação, a verdade somente será aceita se ambos os envolvidos concordarem, ocorrendo a manipulação, ou seja, o destinatário aceita o que lhe é posto, crendo e deixando-se manipular, sendo alvo da persuasão do destinador em seu jogo manipulatório.

Como a manipulação envolve o estabelecimento de um contrato veridictório entre destinador e destinatário, é necessária a aceitação dos valores do primeiro pelo segundo, além deste último exercer um fazer interpretativo que seja da mesma ordem proposta pelo destinador. Nesse processo, o manipulador utiliza a provocação, a tentação, 
a sedução ou a intimidação para obter a adesão do manipulado. Em termos práticos, o autor e a empresa à qual está subordinado, na atualidade, empregam recursos variados para obter e manter o interesse do leitor, como as edições extremamente coloridas, em 3D, com recursos que saltam de dentro do livro quando ele é aberto, além de uma infinidade de outras invenções que não se poderia dizer que atendem aos interesses da criança em formação. Martins (2009, p. 27) ainda aponta que, para evitar a aceitação que muitas vezes atua como doutrinação, é necessário que o destinatário seja um sujeito crítico, capaz de refletir sobre o texto, para que haja uma troca entre ele e o destinador.

No nível discursivo, sob a visão da semiótica, os temas e as figuras são elementos de extrema importância, uma vez que os primeiros tratam do enredo do conto, o porquê de aquela estória ser contada considerando determinados valores em uma época. Embora assuma características diferenciadas que se adequam ao contexto de uma outra época, como no exemplo da Cinderela de Perrault e dos Irmãos Grimm, ou ainda no exemplo de Chapeuzinho Vermelho do primeiro, em cujo final proibido para o século XIX, o lobo, já esperando a menina na cama, diz a ela que se dispa e se deite com ele, em um claro simbolismo do ato sexual. Por outro lado, no conto dos Irmãos Grimm surge a figura do caçador, que mata o lobo e retira a menina e a avó de dentro da barriga do animal, o que, em termos simbólicos, seria um salvador. As figuras do lobo, da menina com a capa vermelha, símbolo da menarca, a avó, que já teria passado pelo mesmo processo, sugerido no conto alemão, e a salvação após terem sido "comidas" pelo lobo, apresenta o traço da continuidade da vida após a agressão sexual. Assim, cada época, de certa forma, emprega a ancoragem a determinados valores, aceitos pela população que os transmite oralmente por meio das estórias.

No nível fundamental estariam os elementos que se opõem na chamada moral da estória, como Bem x Mal, Ingenuidade x Malícia, Erro x Punição etc., constituintes da proposta narrativa de determinado conto.

Também são observados nos contos de fada os recursos empregados na compilação dos contos por um escritor, em determinada época, ou na recriação do conto, no sentido de se encontrar os artifícios e recursos utilizados pelo autor; ou seja, a forma como foi reescrito, a linguagem utilizada, as imagens do livro, a ordenação dos fatos e, principalmente, as bases concretas que possibilitam observar o processo dialógico existente no discurso e as várias vozes ou noções das quais estava imbuído o escritor e que colaboraram para sua visão de mundo ao escrever. Caso tenha uma base necessária para permitir sua percepção da ideologia, dos valores presentes no contexto em que a estória ocorre, o leitor não será um mero objeto de manipulação, mas alguém crítico, capaz de interpretar adequadamente o que lhe é apresentado, chegando a fazer inferências que relacionem a estória, o autor e sua época.

\section{Os contos de fada clássicos e seus compiladores}

Os contos de fada considerados originais ou clássicos e que, na maioria das vezes, são descritos como contos reunidos, tiveram como os mais famosos e conhecidos compiladores, Charles Perrault, Irmãos Grimm e Hans Christian Andersen, mas não se restringem somente a eles, pois houve vários escritores como Joseph Jacobs, Janne-Marie L. Beaumont, Aleksandr Afanasev e outros que contribuíram para a ampliação da literatura infantil como gênero.

Charles Perrault, nascido na França em 1628, foi um dos grandes nomes dessa modalidade literária; oriundo da nobreza formou-se em Direito e atuava a favor da corte no serviço civil, sendo até designado como responsável pela escolha dos arquitetos dos Palácios do Louvre e de Versalhes. Perrault também frequentava os salões literários da 
burguesia, cujos membros eram chamados "preciosistas", graças às frequentadoras denominadas "preciosas ridículas", em uma alusão à peça homônima de Molière, que as via de forma irônica, uma vez que o intelecto da mulher não era valorizado nesse momento histórico. Nessa época, Perrault decidiu publicar Histórias ou Contos do Tempo Passado com Moralidades, ou, como a obra foi conhecida mais popularmente, Contos da Mamãe Gansa, com a primeira edição em 11 de janeiro de 1697.

Sabe-se que a autoria da obra fora atribuída a seu filho caçula, Pierre, mas estudos e pesquisas consideraram improvável a obra ser de Pierre Perrault Darmancout. A coletânea Contos da Mamãe Gansa incluía clássicos como Cinderela, A Bela Adormecida, O Gato de Botas, Chapeuzinho Vermelho, Barba Azul, O Pequeno Polegar, As Fadas e Riquet, o Topetudo. Assim, os contos narrados na cultura popular, foram compilados para satisfazer as necessidades da época em que reinava Luís XIV, o monarca absolutista, considerado como o Rei Sol.

A França era uma sociedade patriarcal, na qual o capitalismo burguês iniciava e se consolidava. A ideologia, caracterizada fundamentalmente pela concepção burguesa de família, fez com que a infância fosse aceita como uma fase significativa da vida, tendo as crianças tratamento diferenciado quanto à educação, por exemplo, pois seriam os disseminadores das ideologias burguesas, segundo Ariès (1981). Dessa forma, a Literatura Infantil ganhou forças, principalmente os clássicos e os contos de fada folclóricos, tendo em Perrault o precursor dessa literatura que objetivava à educação e continha a ideologia da época. Sobre essas mudanças, Tatar esclarece que

Histórias que antes haviam sido vistas como vulgares e grosseiras, com efeitos grotescos e burlescos, foram implantadas no centro de uma nova cultura literária, uma cultura que pretendia socializar, civilizar e educar crianças. Nas estripulias, fugas, aventuras, e romances rocambolescos dos personagens dos contos de fadas, Perrault encontrou uma maneira de ensinar o que importa e como consegui-lo. (TATAR, 2004, p. 355).

Portanto, as estórias de Perrault foram compiladas de acordo com seu público-alvo, o que implicou a modificação de detalhes, que manifestavam características ideológicas, culturais e sociais. $\mathrm{O}$ conto de fada clássico não é somente um mero modelo de estilos ortográficos ou de vocábulos a serem estudados, é também a própria história viva, um meio de relacionar passado e presente.

Jacob Grimm e Wilhelm Grimm, nascidos na Alemanha, em 1785 e 1786 respectivamente, mais conhecidos como Irmãos Grimm, são extremamente populares no universo infantil por causa dos seus contos. Ambos formados em Direito se empenharam nos estudos de história e linguística, através do quais afirmavam ser a cultura popular alemã rica em diversos segmentos, principalmente nos contos outrora passados por gerações.

Assim, dedicaram-se a reunir e compilar os contos populares, que ainda eram encontrados circulando em aldeias e pequenas cidades. Tatar (2004) apresenta uma biografia detalhada de alguns autores infantis e, se referindo aos Irmãos Grimm, denota sua importância na literatura infantil, tendo suas estórias se disseminado por todos os lugares, perpetuando-se no tempo, por meio das diversas formas e aparências, seja em filmes, desenhos, pinturas ou na música.

Contos da Infância e do Lar (Kinder-und Hausmärchen, de 1812) foi o primeiro livro publicado pelos Irmãos Grimm, contendo contos de fadas, fábulas, lendas, piadas, anedotas e outros meios narrativos. Eles procuravam manter as estórias fiéis aos relatos populares, preservando ao máximo esse patrimônio folclórico; no entanto, seus textos continham algumas características que não foram bem aceitas pelos críticos da época, por apresentarem um conteúdo "grosseiro” para as crianças. Assim, após algumas críticas e 
várias reedições do livro, muitos contos foram totalmente transformados para agradar ao público e, principalmente, as crianças.

As estórias de Grimm apelavam ao social e ao religioso, guiados pela ideologia da Igreja Protestante, disseminando valores morais em seus contos, como: família, ética, pátria, trabalho e, principalmente, nas delimitadas definições de gênero da classe média patriarcal. Observa-se também que a punição, a violência e a moral são recorrentes em sua literatura, enfatizando que as pessoas boas e generosas são premiadas, e as malvadas são punidas enfaticamente, havendo, inclusive, algumas cenas de extrema violência (como as invejosas irmãs de Cinderela terem os olhos picados por pombos, ficando cegas, no final), ao contrário das estórias de Perrault (embora neste haja estórias em que a sensualidade esteja marcada). Mesmo assim, seus contos tornaram-se uma espécie de "bíblia" infantil, contados e recontados ao longo do tempo, modificados e usados em outros contextos, mas sempre tendo a base mantida através dos séculos.

Outro escritor muito conhecido no universo da literatura infantil é Hans Christian Andersen. Nascido na Dinamarca, em 2 de abril de 1805, sendo este dia considerado o Dia Internacional do Livro Infanto-Juvenil, tamanha a importância desse escritor nas estórias e contos de fada de seu país. De origem humilde, filho de um sapateiro e de uma lavadeira, Hans, quando jovem, tinha grandes planos de se tornar um ator de teatro, o que o levou a mudar-se para Copenhague, em busca do sucesso. Por meio de amigos que o ajudavam, conseguiu terminar seus estudos na universidade; ao direcionar seus estudos para a literatura, teve prestígio e reconhecimento ainda em vida.

Seu primeiro livro voltado às crianças foi lançado em 1835, intitulado Contos Contados para Crianças, o qual continha estórias como O Isqueiro, As Flores da Pequena Ida, Nicolão e Nicolinho e A Princesa e a Ervilha. Andersen sempre enfatizava que seus contos não eram somente destinados às crianças, mas aos adultos, que poderiam também se entusiasmar e se interessar pelas estórias, pois também poderiam trazer significados para eles.

Ao contrário de Perrault e dos Irmãos Grimm, Andersen sempre afirmava sua autoria nos contos; admitindo que sua inspiração viera das estórias contadas pela sua avó na infância, e que, também, muitas delas apresentavam a sua própria imagem refletida nos personagens. Era uma criança triste, frustrada por ser considerar feio, desengonçado e esquisito, o que se torna evidente em um de seus mais famosos contos, O Patinho Feio, além de muitas outras histórias em que ele projetava uma parte de si, um sentimento, ou uma memória vivida, deixando claro que em suas estórias nem sempre havia um final feliz.

Assim, seus contos são mais voltados aos vícios e às virtudes do ser humano, colocando as personagens de suas estórias em dilemas substanciais. Muitos contos de fada apresentam arquétipos que pouco variam; os de Andersen, ao contrário, refletem contradições, ansiedades e fantasias do autor, que, segundo Tatar (2004), manifestam uma espécie de tribunal de justiça em suas estórias, em que é possível corrigir falhas da vida real na imortalidade de seus textos.

Cunha (1994) enfatiza que antes de distinguir a literatura infantil, as crianças tinham acesso somente à literatura adulta. Foi a partir do século XVIII, com a diferenciação da criança do adulto, que surge uma "educação especial, que a preparasse para a vida adulta" (CUNHA, 1994, p. 22). Assim, também, os contos de fada se tornam uma literatura folclórica, destinada às crianças. Deve-se considerar, porém, que não somente as crianças, mas também os adultos se encantam com os contos de fada e deles abstraem reflexões preciosas sobre o mundo. Como diz Carlos Drumond de Andrade, se uma literatura é boa, não há diferenciação enquanto "literatura", pois o bom livro se dirige a todos:

O gênero "literatura infantil" tem, a meu ver, existência duvidosa. Haverá música infantil? Pintura infantil? A partir de que ponto uma obra literária deixa de constituir alimento para o espírito do adulto? Qual o bom livro que não seja lido para crianças, que não seja lido com interesse pelo homem feito? (ANDRADE, 1944, p. 591). 
Sabe-se que a literatura infantil foi criada pela escola e pela sociedade para incutir nas crianças as lições de moralidade de determinada época. Lajolo enfatiza que esse gênero literário emergiu a partir do "momento em que a sociedade necessitou dela para burilar e fazer cintilar, nas dobras da persuasão retórica e no cristal das sonoridades poéticas, as lições de moral e bons costumes”. (LAJOLO, 2005, p. 22).

\section{A literatura infantil como objeto da indústria cultural}

Ao longo do tempo, a literatura infantil modificou-se, transformou-se e, da mesma maneira, também os contos de fada foram adquirindo características que os diferenciavam dos contos clássicos. Walt Disney foi um dos responsáveis pela completa modificação desses contos que, para atender à demanda de novos valores ideológicos e contextuais, começou a se interessar por essa literatura tão apreciada pelos seres humanos.

Nascido em Chicago, Estados Unidos, Disney foi cineasta, diretor, dublador, animador, roteirista, produtor e um dos maiores nomes do empreendedorismo. Em sua trajetória de vida, descrita por Neal Gabler (2009), em Walt Disney: O Triunfo da Imaginação Americana, o escritor o descreve como uma pessoa persuasiva, entusiasmada, falante, criativa, com um grande poder de imaginação.

Segundo Gabler (2009), a carreira de Walt Disney começou com os desenhos animados, antes preto e branco, que logo ganharam cor, nos quais criou personagens que permanecem até hoje, enraizados não somente na cultura americana, mas em todo o mundo. Entretanto, apesar de ter se tornado referência no imaginário das crianças, dentro do contexto da indústria cultural muitos dos estudiosos de suas criações afirmam que elas não colaboram efetivamente para o desenvolvimento infantil, como afirma Bettelheim:

A pior característica desses livros infantis [de Disney] é que logram a criança no que ela deveria ganhar com a experiência da literatura: acesso a um significado mais profundo e àquilo que é significativo para ela nesse estágio de desenvolvimento. (BETTELHEIM, 2008, p. 11)

O mundo capitalista aceitou totalmente as criações da Companhia Disney; seus desenhos animados influenciaram com características particulares: o embelezamento, inclusive dos contos de fada, fosse por meio de filmes, livros, ou peças de teatro. Além do império de entretenimento e economia construído, a Disney tornou-se um veículo de disseminação de ideologias, em favor do Estado e da promoção dos valores culturais americanos voltados, especificamente, às crianças.

Dessa forma, as animações, com seu caráter persuasivo, modificaram a cultura infantil, fornecendo uma falsa impressão por meio dos belos desenhos, aventuras desejadas, fonte de alegria e prazer, segurança e inocência infantil. Giroux (1997), ao analisar a influência de Disney na cultura infantil, retrata a facilidade com que ele conquistou jovens e crianças, assim como a cultura visual em geral, como a televisão, o cinema, os videogames, shoppings centers e parques de diversão que, “[...] priorizam os prazeres da imagem em detrimento das exigências intelectuais de análise crítica.” (GIROUX, 1997, p. 51)

Do mesmo modo, a Disney representa o domínio capitalista, por meio de seus desenhos animados, estabelecendo relações de poder em torno de políticas e ideologias, que poderiam ser destinadas desde a educação até ao comércio desenfreado de produtos relativos aos personagens Disney.

As fronteiras entre entretenimento, educação e comercialização se confundem, através da absoluta onipotência da intromissão da Disney em diversas esferas da vida coti- 
diana. O alcance do império Disney revela tanto práticas comerciais agressivas quanto um olho clínico para fornecer sonhos e produtos através de formas de cultura popular, nas quais as crianças estão dispostas a investir, material e emocionalmente. (GIROUX, 1997, p. 56).

Os contos de fada abordados nos filmes de Disney, como Branca de Neve, Cinderela, A Bela Adormecida, A Pequena Sereia, A Bela e a Fera, entre outros, são modificados completamente, apelando-se ao estímulo visual, ao invés do intelecto imaginativo. Tal fato gera a crítica de Bettelheim (2008, p. 11), de que contos, com relação à criança, "devem estimular-lhe a imaginação: ajudá-la a desenvolver seu intelecto e a tornar claras suas emoções".

Os contos de Disney diferem dos contos clássicos em vários aspectos, mas o principal fator é o fim econômico. São vários os produtos oriundos dos filmes, desde champanhes infantis, torradeiras, canecas, a notebooks, televisores e decorações de quarto; a variedade é imensa. Sabe-se que grande parte do lucro da empresa provém da venda desses produtos.

Seus filmes, segundo Giroux (1997, p. 71) "[...] sugerem que problemas sociais tais como a história do racismo, o genocídio dos índios americanos, a prevalência do sexismo e a crise da democracia são resolvidos simplesmente através das leis da natureza."

Neto (2013), em um artigo publicado no blog "Rainhas Trágicas", intitulado Enquanto a Aurora dormia, ilustra claramente as diferenças entre os clássicos e as adaptações realizadas pela Disney, analisando o enfoque do filme A Bela Adormecida (1959) e a posição crítica da companhia frente ao feminismo que, na época do lançamento do filme, ganhava as ruas do mundo.

O autor esclarece que, se analisado criticamente, o conto original e o filme Disney se diferenciam, pelo enfoque e pelo contexto serem outros. A bruxa do filme, Malévola, além de ser representada com um estereótipo demoníaco, é também uma mulher solteira, com muito trabalho para fazer e problemas para resolver, mas que ao final é "vencida". Assim, a estória se desenvolve ante o enfoque do matrimônio e o sistema que regeu a sociedade durante anos, no qual a mulher desempenhou função submissa e secundária, como aquela a que está relegada a ela que dorme todo o tempo.

Portanto, reconhecer e ser crítico frente às relações de conhecimento e poder existentes nos filmes, e em suas mensagens ideológicas, e conhecer a relação entre o governo norte-americano e a Disney são processos fundamentais para se debater a respeito dessa nova cultura infantil, tornando-se os contos objeto de diálogo referente às novas adaptações.

Assim como Giroux (1997), Pierre Lévy (1999) reconhece a importância do professor nesse processo. No caso do uso de filmes na educação, enfatizam que o professor deve estar empenhado em proporcionar incentivos para o pensamento e a aprendizagem do aluno, incitando "[...] à troca troca de saberes, a mediação relacional e simbólica, e a pilotagem personalizada dos percursos de aprendizagem." (LÉVY, 1999, p. 171).

\section{Considerações finais}

Atualmente, com o surgimento de diversos meios eletrônicos, bem como com o advento da internet, o conhecimento está acessível para todos. Os contos de fada de Perrault, Grimm e Andersen, assim como os de Disney, além de outras literaturas, estão disponíveis para quem desejar. Assim, torna-se essencial o trabalho com esses contos a partir de leituras críticas dos professores para com os alunos, pois essas leituras, por exemplo, de ideologias de diferentes contextos, em que nada pode ser visto em sua superficialidade. Isso proporciona às crianças a possibilidade de cada uma em seu nível, entrar em contato com os mais diversos contos, conhecendo a sabedoria destes. 
A literatura infantil utiliza-se do fato de não haver neutralidade na linguagem, uma vez que o enunciador se expressa de acordo com seu histórico de mundo e com a ideologia adotada. Dessa forma, ao se utilizar a linguagem como recurso discursivo, deve haver uma profunda análise crítica acerca de seu emprego, observando-se a ideologia que transmite e todas as mensagens ocultas no nível subliminar.

Quanto ao que se pretende acerca do significado dos textos, cabe ao professor analisar os contos que pretende utilizar em sala de aula, a partir de um olhar cuidadoso, para que essas histórias, seja na escola, na família ou em outros veículos de circulação, se transformem em algo significativo para quem as lê, permanecendo no inconsciente individual, a partir do que é obtido do inconsciente coletivo, pois estão carregadas de significados que interferem nos níveis psicológicos do ser humano. Segundo Machado,

\begin{abstract}
É para isso que o homem conta histórias - para tentar entender a vida, sua passagem pelo mundo, ver na existência alguma espécie de lógica. Cada texto e cada autor lidam com elementos diferentes nessa busca, e vão adequando formas de expressão e conteúdo de um jeito que mantém uma coerência interna profunda que lhe dá sentido, mexer neles é alterar esse sentido. Muitas vezes, equivale a transformar a nova versão em alguma coisa esdrúxula, sem pé nem cabeça. (MACHADO, 2002, p. 75).
\end{abstract}

A importância de se resgatar os contos de fada clássicos deve-se ao fato de serem narrativas construídas há séculos, portadoras de arquétipos que falam ao inconsciente coletivo, suprimindo as necessidades psicológicas do ser humano. Modificar essas versões, deixando-as vazias de significado, é levar os leitores desses contos a acreditar que tudo é maravilhoso, sendo que o mundo real não é. É basicamente tirar o suporte que fará a criança perceber que a vida é complicada, sim, com muitas dificuldades e com obstáculos, mas que no final pode ser vitorioso aquele que aprender a lidar com as adversidades, a superar os obstáculos e a ser persistente na busca por seus objetivos, como ocorre com os heróis dos contos de fada.

\title{
Referências
}

ANDRADE, Carlos Drummond de. Confissões de Minas. Rio de Janeiro: Americ, 1944.

ARIES, Philippe. História social da criança e da família. Rio de Janeiro: LTC, 1981.

BARROS, Diana Luz Pessoa de; FIORIN, José Luiz (Org.). Dialogismo, Polifonia, Intertextualidade. São Paulo: Editora da Universidade de São Paulo, 1999.

BETTELHEIM, Bruno. A psicanálise dos contos de fadas. Rio de Janeiro: Paz e Terra, 2008.

CORRALES, Luciano. A intertextualidade e suas origens. In: SEMANA DE LETRAS, 10., 2010, Porto Alegre. Anais da X Semana de Letras. Porto Alegre: EDIPUCRS, 2010. Disponível em: <http:// ebooks.pucrs.br/edipucrs/anais/Xsemanadeletras/comunicacoes/Luciano-Corrales.pdf $>$. Acesso em: 22 out. 2011.

CUNHA, Maria Antonieta Antunes. Literatura infantil: teoria e prática. São Paulo: Ática, 1994.

FIORIN, José Luiz. Introdução ao pensamento de Bakhtin. São Paulo: Ática, 2006.

GABLER, Neil. Walt Disney: O triunfo da imaginação americana. Osasco: Novo Século, 2009.

GIROUX, Henry. Os professores como intelectuais: rumo a uma pedagogia crítica da aprendizagem. Porto Alegre: Artes Médicas, 1997.

KRISTEVA, Julia. La sémiologie: science critique ou critique de la science. In: Théorie d'ensemble. Paris: Seuil, 1968. p. 80-93. 
LÉVY, Pierre. Cibercultura. São Paulo: Editora 34, 1999.

LAJOLO, Marisa. Do mundo da leitura para a leitura do mundo. São Paulo: Ática, 2005.

MACHADO, Ana Maria. Como e por que ler os clássicos universais desde cedo. Rio de Janeiro: Objetiva, 2002.

MARTINS, Maria Angélica Seabra Rodrigues. Aprender a pensar: um desafio para a produção textual. Bauru: Canal 6, 2009.

.Ética, educação e aprendizagem no Brasil - escolanovismo, ditadura militar, contexto atual. São Paulo: Cultura Acadêmica, 2012.

MARX, Karl; ENGELS, Friedrich. Textos sobre educação e ensino. São Paulo: Moraes, 1992.

NETO, Renato Drummond Tapioca. Enquanto Aurora dormia... 2013. Disponível em: <http:// rainhastragicas.com/2013/05/09/enquanto-a-aurora-dormia/>. Acesso em: 15 out. 2013.

TATAR, Maria. Contos de Fadas: edição comentada e ilustrada. Rio de Janeiro: Zahar, 2004. 
